\title{
Dossiê
}

\section{Os coletivos em cena: experiências práticas e campo de análise}

\author{
The collectives on the scene: practical experiences and \\ field of analysis
}

Los colectivos en escena: experiencias prácticas y campo de análisis

\section{Comissão Organizadora}

Prof $^{\mathrm{a}} \mathrm{Dr}^{\mathrm{a}}$ Maria da Glória Gohn - Universidade Estadual de Campinas, Brasil Prof. Dr. Claudio Luis de Camargo Penteado - Universidade Federal do ABC, Brasil Prof. Me. Marcelo de Souza Marques - Universidade Federal do Rio Grande do Sul, Brasil

Nos últimos anos, as análises sobre as novas experiências organizacionais e de ação da sociedade civil contemporânea, e suas inter-relações com a esfera estatal, têm sido um dos temas centrais nos estudos de Ciências Humanas e Sociais no Brasil e no mundo. O ciclo de protestos, que ocorreu entre os anos de 2010 a 2016, em diversas partes do mundo, deu visibilidade à emergência dessas experiências. No Brasil, esse ciclo ganhou expressão a partir de junho de 2013, com a explosão de manifestações por todo o país, surgindo uma diversificada agenda de pesquisa.

Ainda que não existam relações diretas ou "necessárias" entre a emergência de novas experiências organizacionais e o ciclo de protestos, foi naquele contexto, em especial, que 
ficaram mais perceptíveis aos analistas os processos de estruturação de novas estratégias, modelos de organização menos hierárquicos, performances e discursos presentes nas mais diferentes mobilizações societárias. Além disso, como observa Perez (2019), é preciso ponderar o contexto estratégico-relacional e os novos "incentivos" às mobilizações e à ressignificação de repertórios potencializados desde aquele período. Havia um contexto marcado de crítica aos espaços tradicionais de participação e representação política, questionamentos sobre as estruturas de organizações históricas, como partidos políticos, sindicatos, ONG's e mesmo de certas organizações de movimentos sociais percebidos por muitos ativistas como estruturas hierarquizadas, altamente burocráticas e centradas na ideia de lideranças formais (Borelli et. al., 2010; Gohn, 2017; 2019; Perez, 2019). Do mesmo modo, havia também o cenário de emergência de uma nova estrutura de comunicação digital, estruturada em redes distribuídas de comunicação, que altera o fluxo de comunicação (Benkler, 2006) e permite que os diversos segmentos sociais participem ativamente do debate público por meio do processo de autocomunicação de massa, conforme argumenta Castells (2013).

Dentre as experiências de organização e de ação da sociedade civil que passaram a reconfigurar tanto o cenário político-organizacional quanto as reflexões teórico-analíticas sobre as mobilizações, os protestos e as experiências organizacionais, registram-se os "coletivos". Embora os coletivos - pensados mais amplamente como experiências organizacionais inspiradas em princípios autonomistas, na organização horizontal e na desconstrução da ideia de liderança formal e vertical - não sejam um fenômeno inerente ao momento presente, portanto, sem relações com experiências anteriores, a atenção dispensada a este fenômeno ressurgiu muito recentemente, no Brasil, como uma nova agenda de pesquisa. Como toda "novidade" em análise, a literatura e o campo de estudos sobre os coletivos ainda é um esforço em construção e em expansão, com o desenvolvimento de novas abordagens e métodos de pesquisa, que visam dar conta das inúmeras formas de "coletivos".

Visando contribuir com o debate, mas também com a construção de um campo de estudos voltados à análise dos coletivos, em suas múltiplas dimensões, experiências e vivências, é que foi organizado o presente dossiê Os coletivos em cena: experiências práticas e campo de análise. Os trabalhos aqui reunidos voltam-se ao desenvolvimento de novas abordagens e categorias analíticas para: a construção de metodologias voltadas à apreensão do fenômeno, bem como à identificação das inovações (e continuidades) que os coletivos trazem para a ação coletiva, e os limites e potencialidades da ação política desses grupos; a compreensão da relação conflitiva com as institucionalidades; os estudos comparativos entre 
diferentes modelos de organização e atuação dos coletivos e entre os coletivos e organizações da sociedade civil; e outras formas de apreensão e análise dos coletivos.

Superando a perspectiva inicial, tivemos a grata surpresa de contar com mais de trinta submissões em um curto período de recebimento de propostas - cerca de cinco meses. Foram submetidos trabalhos que analisavam o contexto brasileiro, argentino, espanhol e português, a partir de diferentes áreas do conhecimento, tais como Administração, Antropologia, Artes e Cinema, Ciência Política, Comunicação Social, Educação, Planejamento Urbano/Políticas Públicas, Psicologia e Sociologia. Ao todo, foram aprovados doze trabalhos. Sendo que dois serão publicados nas edições do próximo ano devido a alguns atrasos no processo de revisão final dos artigos.

Abrindo o dossiê, contamos com a colaboração de Marcelo Marques (UFRGS) e Vanessa Marx (UFRGS), com o artigo "Os coletivos em cena. Algumas contribuições para o debate". O objetivo do artigo consistiu em uma sistematização de alguns dos elementos centrais da recente literatura sobre coletivos que poderiam auxiliar um exame mais detido sobre essas experiências organizacionais e em uma análise discursiva do processo de identificação dos sujeitos como coletivos. Como destacam os autores, considerando os achados da literatura e os primeiros dados da pesquisa de doutorado em andamento, o argumento estruturante da análise é que a construção da ideia de coletivo também significa a demarcação de uma posição diferencial em relação a outras experiências associativas. Ou seja, pensar os coletivos exige considerar a forma como os sujeitos significam outras experiências associativistas, como partidos, sindicatos etc.

Na sequência, temos o trabalho de Flavia de Faria (USP/EHESS, França). Em seu artigo "Epistemologia emancipatória de coletivos políticos", Faria parte das manifestações de junho de 2013 como um ponto de inflexão para o surgimento acentuado de mobilizações que contribuem para uma ampla reconfiguração do ativismo social. Para a autora, tal processo implica, por um lado, a busca da horizontalidade, autonomia e participação. Por outro lado, considera que a experimentação de outra forma de organização interna, de relações de poder e de tomada de decisões significa conceber, na prática e no quotidiano, outro "espaço de aparecimento": tornar visíveis corpos dissidentes, reivindicar a legitimação e o reconhecimento de identidades e culturas historicamente subjugadas. O objetivo do artigo é analisar o conceito de "coletivos políticos" como sendo aqueles que atuam diretamente com as clivagens sociais.

Abrindo os artigos que apresentam análises de caráter mais empírico, contamos com o trabalho de Mariana Zanata Thibes (UFABC/PUC-SP), Rosemary Segurado (PUC-SP), 
Natasha Pereira Bachini (IESP-UERJ/FESPSP) e Tathiana Senne Chicarino (FESPSP/PUCSP), intitulado "Movimentos sociais e coletivos no Brasil contemporâneo: horizontalidade, redes sociais e novas formas de representação política". O trabalho das autoras apresenta os resultados de uma pesquisa empírica feita com atores coletivos de diversas regiões do Brasil, a partir da análise de entrevistas realizadas nos estados de São Paulo, Bahia, Maranhão, Rio Grande do Sul, Ceará e Mato Grosso do Sul. Com o objetivo de observar os variados modos contemporâneos de ativismo político e cultural no país, as pesquisadoras destacaram os sujeitos que emergiram na disputa política recente com foco na crítica à representação, atentando especialmente para os coletivos. O artigo aborda questões sobre a estrutura, a organização, a concepção da ação política e coletiva, o papel das "lideranças" e as formas de comunicação das organizações.

Na continuidade da apresentação, temos o artigo "Coletivos e o ciclo de protestos dos anos 2010: reflexões sobre horizontalidade e as tecnologias digitais da informação e comunicação", de autoria de Caio Becsi Valiengo (UFABC) e Marília Jahnel de Oliveira (UFABC). Com o foco no uso que os coletivos fazem das tecnologias digitais da informação e comunicação (TDICs), os autores destacam a complexidade e a pluralidade desta forma de organização e ativismo social que se organiza de forma horizontal e colaborativa pelo uso das tecnologias digitais de forma instrumental, estratégica e criativa. $\mathrm{O}$ artigo apresenta o estudo das práticas organizativas e de atuação política desses grupos, as quais foram analisadas a partir de material resultante de pesquisa realizada com cinco coletivos que atuam na cidade de São Paulo em diálogo com uma retomada histórica do ciclo de protestos dos anos 2010, apresentando uma perspectiva histórica e processual das lutas coletivas. O debate sobre a relação entre horizontalidade, TDICs e formas de liderança busca analisar a construção de práticas horizontais e colaborativas, indicando convergências entre as experiências do ciclo e as práticas dos coletivos, contribuindo para a reflexão sobre o cenário contemporâneo de ação coletiva.

Também considerando o ciclo de protestos dos anos 2010, de inspiração autonomista e altermundista, Lucca Amaral Tori (USP), Luana Hanaê Gabriel Homma (UFABC) e Giuliana Fiacadori (UFABC), no artigo "Coletivos e o uso das redes: o caso das ocupações das escolas de São Paulo em 2015”, destacam o uso das redes sociais de internet nas experiências das organizações coletivas de estudantes durante o processo de ocupações de escolas em 2015, a partir de um estudo comparativo das páginas de Facebook "O Mal Educado" e "Não Fechem Minha Escola". A metodologia utilizada incluiu entrevistas com administradores e análise de conteúdo de 50 publicações com maior engajamento de cada página. Como destacam os 
autores, as páginas diferem em relação à visão sobre estratégia de comunicação, composição da administração e quanto às redes às quais pertenceram no movimento.

$\mathrm{Na}$ sequência, temos a contribuição de Paulo Edgar da Rocha Resende (PUC-SP), Maria Luiza Pereira Pacheco (UC, Portugal) e Valéria Barros dos Santos Marchesi (UVV), com o artigo "Multiplicidade Política entre as Capturas e as Resistências dos Novíssimos Movimentos Sociais e Coletivos da Grande Vitória". Atentos ao ativismo contemporâneo e suas inovações, considerando os diferentes repertórios organizacionais, relacionais e de ação, os autores analisam as experiências de coletivos e movimentos na Grande Vitória, Espírito Santo, em meados de 2013. Com distintas técnicas de coleta de dados e análise baseada em proposições políticas pós-estruturalistas, Rezende, Pacheco e Marchesi discutem as inovações e as singularidades dos grupos considerando seus potenciais de provocar transformações sociais. Para os pesquisadores, as maiores inovações e potenciais foram localizadas naqueles que se podem denominar novíssimos movimentos sociais e coletivos.

Dando continuidade, no artigo "Coletivismo juvenil em Teresina: desenhando um panorama a partir das mídias sociais Instagram e Facebook", Kary Emanuelle Reis Coimbra (UFIP) e Maria Dione Carvalho de Morais (UFIP) analisam a expansão de coletivos/coletivas juvenis na cidade de Teresina, Piauí, nos anos 2010, o que levou as autoras a indagarem sobre sua presença no ciberespaço por meio de mídias sociais e sobre suas pautas de ação política e campos de atuação. Partindo de um levantamento nas mídias sociais Facebook e Instagram, Coimbra e Morais identificaram 27 páginas de coletivos, cujas postagens escritas e imagéticas foram metodologicamente tomadas como práticas discursivas. Como resultados, as pesquisadoras constataram a autodenominação coletivo/coletiva pela quase totalidade dos agrupamentos; o uso de ambas as mídias ou de apenas uma delas; a diversidade de campos de atuação/pautas e suas convergências; os marcadores identitários; e os objetivos, explícitos ou implícitos, de atuação voltada à crítica social, à desconstrução/reconstrução de padrões socioculturais e a projetos emancipatórios.

O sétimo artigo do dossiê, "O coletivo Critical Art Ensemble e a estética do distúrbio", de autoria de Lucas Fortunato Rêgo de Medeiros (UFRN) e Alexsandro Galeno Araújo Dantas (UFRN), analisa as ações do referido coletivo cultural a partir de uma perspectiva micropolítica e suportes teóricos da sociologia, da história e da crítica da arte contemporânea. Considerando a existência de experiências coletivas anteriores no campo das artes, os autores abordam o Critical Art Ensemble (CAE) a partir do que denominam de "neocoletivismo", compreendido como um fenômeno sociológico emergente nas décadas recentes, e exploram algumas de suas formas de expressão, por meio de um estudo de caso baseado em uma 
pesquisa bibliográfica e documental. Os dados analisados permitiram compreender a trajetória do coletivo, sua forma de se organizar, criar e agir na esfera da cultura. Os resultados da pesquisa demonstram que o CAE é um caso exemplar do neocoletivismo, tendência caracterizada por formas de atuação intervencionistas em que estética e política tornam-se, por vezes, indiscerníveis em suas expressões semióticas e culturais.

Na sequência, contamos com a colaboração de Helena Motta Monaco (UFSC), com o artigo "colhimento como ativismo: ações de um coletivo bissexual na criação de espaços "monodissidentes"'. O artigo tem como objeto de estudo a atuação de um coletivo bissexual da cidade de São Paulo, tendo por objetivo explorar a bissexualidade enquanto organização política, em especial no que diz respeito à criação de espaços de acolhimento. Como destaca a autora, a pesquisa foi realizada por meio de entrevistas semiestruturadas com doze ativistas, além de observação participante em uma atividade presencial e análise de documentos publicados pelo coletivo. Monaco informa que foi constatado que o coletivo adota uma política de "biolegitimidade" à medida que reivindica direitos às pessoas bissexuais, afirmando a existência de um sofrimento que teria origem na bifobia que as vitimiza. A pesquisadora argumenta que os seus interlocutores utilizam a noção de "descoberta da bissexualidade", na qual encontrar acolhimento em uma comunidade bissexual, organizada na forma de coletivo, aparece como um fator fundamental para a construção de uma identidade bissexual e para o combate ao sofrimento psíquico.

Fechando as contribuições do dossiê, Milena Geisa dos Santos Martins (UFRJ/CRELIG) apresenta o interessante artigo "Coletivos quebrando o silêncio: mulheres feministas e evangélicas na luta contra a violência de gênero e em favor à legalização do aborto". Por meio de entrevistas e netnografia, a autora apresenta que a partir dos espaços religiosos também emergem coletivos, cujas vozes dissonantes não compactuam com a subjugação feminina comumente implementada pela religião, contrariando uma visão generalista do senso comum. Martins nos mostra como esses coletivos denunciam, em ambientes virtuais, a violência praticada contra a mulher em nas esferas doméstica ou eclesiais. Destaca, também, que além de trabalharem voluntariamente, instruindo e acolhendo vítimas de violência, as Feministas Evangélicas, pesquisadas pela autora, lutam em favor da legalização do aborto, pois entendem que esta é uma questão de saúde pública. Porém, mesmo lutando em favor dos direitos femininos, Martins nos mostra que elas são ameaçadas por indivíduos que possuem ethos familista e visão conservadora de mundo, pois estes entendem que elas querem destruir a família. 
Este dossiê traz contribuições inéditas para o campo de pesquisa não somente em torno dos coletivos, mas também para a ampliação da compreensão e análise da ação coletiva na sociedade contemporânea. A diversidade dos textos que compõem este dossiê ilustra a complexidade que envolve o estudo dessa forma de organização social, política e cultural. Os coletivos podem ser vistos como uma expressão de uma nova configuração social mais difusa e fluída, que questiona e tensiona as estruturas políticas, econômicas, sociais e culturais tradicionais. Como evidenciam os artigos, as práticas dos coletivos apresentam continuidades e descontinuidades de uma agenda de pesquisa interdisciplinar, ainda em formação, com importantes desafios para os pesquisadores e pesquisadoras de diferentes áreas do conhecimento.

Desejamos a todos(as) uma excelente leitura!

Com os melhores cumprimentos.

Os Organizadores

Vitória, Brasil, 14-12-2020 